\title{
Release of Cardiac Biomarkers during a Cycling Race
}

\author{
Caroline Le Goff'1, Jean-François Kaux ${ }^{2}$, Stéphanie D’Otreppe ${ }^{1}$, Sébastien Goffaux ${ }^{2}$, \\ Marianne Fillet ${ }^{3}$, Jean-Paul Chapelle ${ }^{1}$, Etienne Cavalier ${ }^{1}$ \\ ${ }^{1}$ Department of Clinical Chemistry, University of Liège, Liège, Belgium \\ ${ }^{2}$ Department of Physical Medicine and Sport Traumatology, SPORTS ${ }^{2}$, FIFA Medical Centre of Excellence, \\ University of Liège, Liège, Belgium \\ ${ }^{3}$ Department of Analytical Pharmaceutical Chemistry, University of Liège, Liège, Belgium \\ Email: c.legoff@chu.ulg.ac.be
}

Received 31 May 2016; accepted 16 August 2016; published 19 August 2016

Copyright (C) 2016 by authors and Scientific Research Publishing Inc.

This work is licensed under the Creative Commons Attribution International License (CC BY).

http://creativecommons.org/licenses/by/4.0/

(c) (i) Open Access

\begin{abstract}
Objectives: Over the past two decades, a large interest in cardiac marker elevations has developed in endurance sports events. The intense effort is not without risk. We aimed to see if the relatively cardiospecific biomarkers could show the damage on cardiac muscle cells. Methods: Fourteen cyclists were recruited for an international race $(177 \mathrm{~km})$. We studied different cardiac biomarkers, renal function markers and blood cytology. The subjects were submitted to three blood test: one before (T0), one just after (T1) and the last one 3 hours after the race (T3). Results: Blood cytology markers, namely erythrocytes, hemoglobin, hematocrit, and average hemoglobin concentration, were found to evolve in a similar way. Renal function markers, such as creatinin, cystatin C and uric acid, showed a post effort increase that might be related to renal blood flow depletion during exercise. Cardiac and muscular markers were all increased at T1. Conclusions: Physiological stress induced by an international cycling race certainly has consequences on cardiac muscle cells. Fortunately, those blood concentration variations are more representative of a transitional state, due to an imbalance created by an intense aerobic effort maintained during several hours, rather than an irreversible injury.
\end{abstract}

\section{Keywords}

Cycling, Cardiac Biomarkers, Stress Biomarkers, Renal Function Markers

\section{Introduction}

“Cardiovascular Diseases” (CVD) represent the first cause of death in numerous developed countries, preceding

How to cite this paper: Le Goff, C., Kaux, J.-F., D’Otreppe, S., Goffaux, S., Fillet, M., Chapelle, J.-P. and Cavalier, E. (2016) Release of Cardiac Biomarkers during a Cycling Race. World Journal of Cardiovascular Diseases, 6, 285-294. 
cancer and accidents [1]. Nowadays, mortality due to cardiac events tends to be stabilized. This is notably the consequence of prevention campaigns against obesity, smoking and sedentary lifestyle, as well as to the improvement of imaging and diagnostic approaches. In spite of these progresses, cardiovascular diseases (CVD) incidence remains high because of the increase in life expectancy, and in diabetes and obesity incidence.

World Health Organisation recommendations [1] concerning the practice of physical activity are clearly established for healthy adults aged between 18 and 64 years old: to obtain maximal benefits, they should ideally perform, over one week, at least 300 minutes of moderate-intensity endurance based physical activity or, at least 150 minutes of high-intensity endurance based physical activity [2]. It has been demonstrated that, following a lengthy and intense strain, some biological parameters (electrolytes, cardiac markers) can be modified in participants when compared to a state of rest. In general, these values return to a normal state within 24 - $48 \mathrm{~h}$ after the exercise, which suggests that these effects are just transient. This might be explained by the relatively short half-life of studied markers, or water imbalance during and after the event.

Amateur and elite/hope cyclists usually submit themselves to physical training activities largely surpassing the aforementioned criteria [3]. Over a week, these athletes sometimes spend more than 20 hours of training dedicated to cycling. The impact of such a stress must inevitably have consequences, positive or negative, on their organism, particularly on the heart.

Formerly used in the acute coronary syndrome (ACS) diagnostic, "cardiac enzymes" (creatine kinase (CK), aspartate aminotransferase, lactate dehydrogenase, myoglobin...) are not used anymore in this framework, being totally lacking in cardiospecificity [4] [5]. Regarded erstwhile as the cardiac "gold standard", isoform CK-MB determination is nowadays only recommended if troponin determination is not available. Indeed, its cardiospecificity is affected by its presence in the skeletal muscle. High sensitivity cardiac troponins T and I (hsTnT and hsTnI) are currently regarded as reference markers of myocardic necrosis on the basis of their excellent sensitivity and cardiospecificity [6]-[10]. New independent markers of the cardiovascular risk, related to the troponins, have newly been developed.

However, the risk of cardiac events or sudden death after a vigorous physical effort has been described in multiple previous studies [11]-[13]. Some papers already reported the impact of intense exercise on specific cardiac biomarkers, such as NT-proBNP and hsTnT [14]. Brain Natriuretic Peptide is synthesized by cardiomyocytes [15]. High blood concentrations reflect a high myocardial after load parietic tension due to the stretching of the myocytes. This stretching is caused by an increase in pressure and/or volume or by a neuro-hormonal activation in case of heart dysfunction, heart failure, cardiomyopathies, acute coronary syndromes as well as other cardiac syndromes [16]. As a marker of heart dysfunction, B-type natriuretic peptide (BNP) and N-terminalpro-B-type natriuretic peptide (NT-proBNP) provide a useful tool for the diagnosis of cardiovascular disease, for the monitoring of drug therapy and for risk stratification [5]. Although the exact mechanism of troponins release has not yet been made clear, its elevation is either due to necrosis of the cardiomyocytes (irreversible injuries), or to a transitory and reversible modification of their membrane permeability [17]. In a general population, an elevation above the 99th percentile of the reference population involves a bad prognosis [18], but this level is exceeded in many studies after strenuous exercise [19] [20]. Using this ultra-sensitive assay allows to decrease the limit of detection, so it makes it possible to establish an early diagnosis of a myocardial infarction in relation to the standard Troponin $\mathrm{T}$ ( $\mathrm{cTnT}$ ) assay, the prognosis being more precise when the diagnosis is formulated as early as possible.

These emergent markers are likely to bring additional prognostic and diagnostic values in the estimation of cardiovascular risk. The possibility to measure high sensitive troponin $\mathrm{T}$ allows us to detect minimal increases in concentration.

As in the news, we have read some case of sudden death in competition sports, it could be important to find a potential biomarker or an association of different biomarkers that could highlight subjects at risk. The aim of this paper was to study the kinetics of the different biomarkers and particularly of specific cardiac biomarkers in young competitive cyclists and try to objectify if they are representative of cardiac damages during a strenuous exercise.

\section{Methods}

All experimental procedures and protocols used in this investigation were reviewed and approved by the Ethics Committee of the University of Liège (Belgium). A group of fourteen competitive cyclists from elite/hope levels and amateur Belgian categories were enrolled in our study after they gave informed consent. The competition 
was "La Flèche Ardennaise”, a race of 176.9 kilometers. The group of individuals was selected for maximal homogeneity. Their annual training volume was between 10,000 and 16,000 kilometers in 4 to 6 training sessions per week. Excluding the 2-month winter period, this represents a monthly average of 1000 to 1600 kilometers.

The rhythm of races is comparable and averages $35 \mathrm{~km} / \mathrm{h}$, depending on the race's difficulty. In fact, the evening before such an event cyclists had the habit of going out for a short, low intensity workout intended to stimulate muscle groups for the following day.

The cardiac frequency was recorded via a cardio-frequency meter.

Three blood tests were taken. The first blood test, $\mathrm{T}_{0}$, was taken approximately 2 hours before the start of the race and was intended to gather values which would act as references for the following tests. The second blood test, T1, was realized within 5 minutes of their arrival (mean $4 \mathrm{~h} 50 \mathrm{~min} 34 \mathrm{sec}$ ). The third and final blood test, T3, was taken 3 hours following their arrival. The High sensitive C-reactive protein (hsCRP), NT-proBNP, CK and CK-MB, myoglobin (MYO) were measured on the Roche Diagnostic modular E (Manhein, Germany). The blood cytology, composed of erythrocytes, hemoglobin, hematocrit, was performed on the Sysmex Cellavision (Kobe, Japan). Homocystein (HCY) and Cystatin C (CysC) were analysed on the BNII (Siemens, Munich, Germany). All automated assays were performed according to the manufacturer's specifications. An absorbance measure was carried out after lysis of the red blood cell for erythrocytes, hemoglobin and hematocrit on the Sysmex Cellavision (Kobe, Japan). The biochemistry parameters as creatinin was measured by colorimetry, uric acid by spectrophotometry, CK by photometry, hsTnT, NT-proBNP, MYO and CK-MB by electrochemiluminescence on the Roche Diagnostic modular E (Manhein, Germany). The HCY determination was performed by liquid chromatography coupled to a fluorescent detector. Cystatin $\mathrm{C}$ were determined by nephelometry on the BNII (Siemens, Munich, Germany).

For the statistical analysis, an ANOVA and post hoc test of Scheffé were calculated with the Statistica Software version 9.1. Results were considered significant at the level of uncertainty of $5 \%(\mathrm{p}<0.05)$.

\section{Results}

Before sixteen cyclists participated at the start of our study but two subjects dropped out. Fourteen cyclists finished the race (mean time to do the race was 4 h 50 min; mean speed of $35 \mathrm{~km} /$ hour). Their main biometric and physiological characteristics are shown in Table 1 . We noticed an important significant variation in the cardiac frequency between T0 and T1 ( $\mathrm{p}<0.0001)$, T0 and T3 ( $<<0.0001)$, and T1 and T3 (p = 0.006).

Table 2 shows the results obtained for the different biomarkers. We observed an important variation of the red blood cell concentration between T0 and T3 $(p=0.0026)$, as well as a significant increase in hemoglobin between T0 and T3 ( $\mathrm{p}=0.002)$. Hematocrit significantly increased between all times ( $<<0.0001$ between T0 and T3, $\mathrm{p}=0.0451$ between $\mathrm{T} 0$ and $\mathrm{T} 1$ and $\mathrm{p}=0.029$ between $\mathrm{T} 1$ and $\mathrm{T} 3)$. We observed significant variations for creatinin and cystatin $\mathrm{C}$ between all times T0 - T1: $\mathrm{p}<0.0001$, T1 - T3: $\mathrm{p}=0.0326$ and T0 $-\mathrm{T} 3 \mathrm{p}=0.0001$, and T0 - T1: $\mathrm{p}<0.0001$ and T0 - T3: p $<0.0001$ respectively. Uric acid showed a significant difference between T0 and T1 ( $<<0.0001)$ and between T0 and T3 ( $<0.0001)$. Myoglobin increased significantly between T0 and T1 ( $<<0.0001)$. Myoglobin levels then decreased between T1 and T3 with the T3 levels remaining higher than T0 ( $\mathrm{p}=0.014)$. HsTnT increased significantly between T0 and T1 ( $<0.0001)$ and stayed high 3 hours after the end of the exercise (T0 - T3: $\mathrm{p}<0.0001$ ) (Figure 1).

At T0, the values obtained for NT-proBNP showed an average value of $40,8 \pm 9 \mathrm{pg} / \mathrm{ml}$. The reference values established in our laboratory are $5-103 \mathrm{pg} / \mathrm{ml}$ for the age range that we analysed. The values obtained from our subjects were thus inside the normal range, but we noted an increase with time. Some subjects were above the upper reference value at $\mathrm{T} 1$ (average value at $\mathrm{T} 1: 80.6 \pm 16 \mathrm{pg} / \mathrm{ml}$ ). The intense exercise produced during the race induced a significant variation of NT-proBNP. We observed the same kinetic as for HsTnT. We noticed statistically significant variation between T0 and T1 (p = 0.0037) and between T0 and T3 (p = 0.0432) (Figure 2). The last parameter showing a significant variation in time was homocystein, with an increase between T0 and

Table 1. Main biometric characteristics of our studied population.

\begin{tabular}{ccccc}
\hline & Height $(\mathrm{m})$ & Weight $(\mathrm{kg})$ & Age (yo) & Heart rate (BPM) \\
\hline Mean & 179.8 & 69.6 & 25.1 & 58 \\
SD & 7.4 & 7.8 & 6.4 & 10 \\
\hline
\end{tabular}




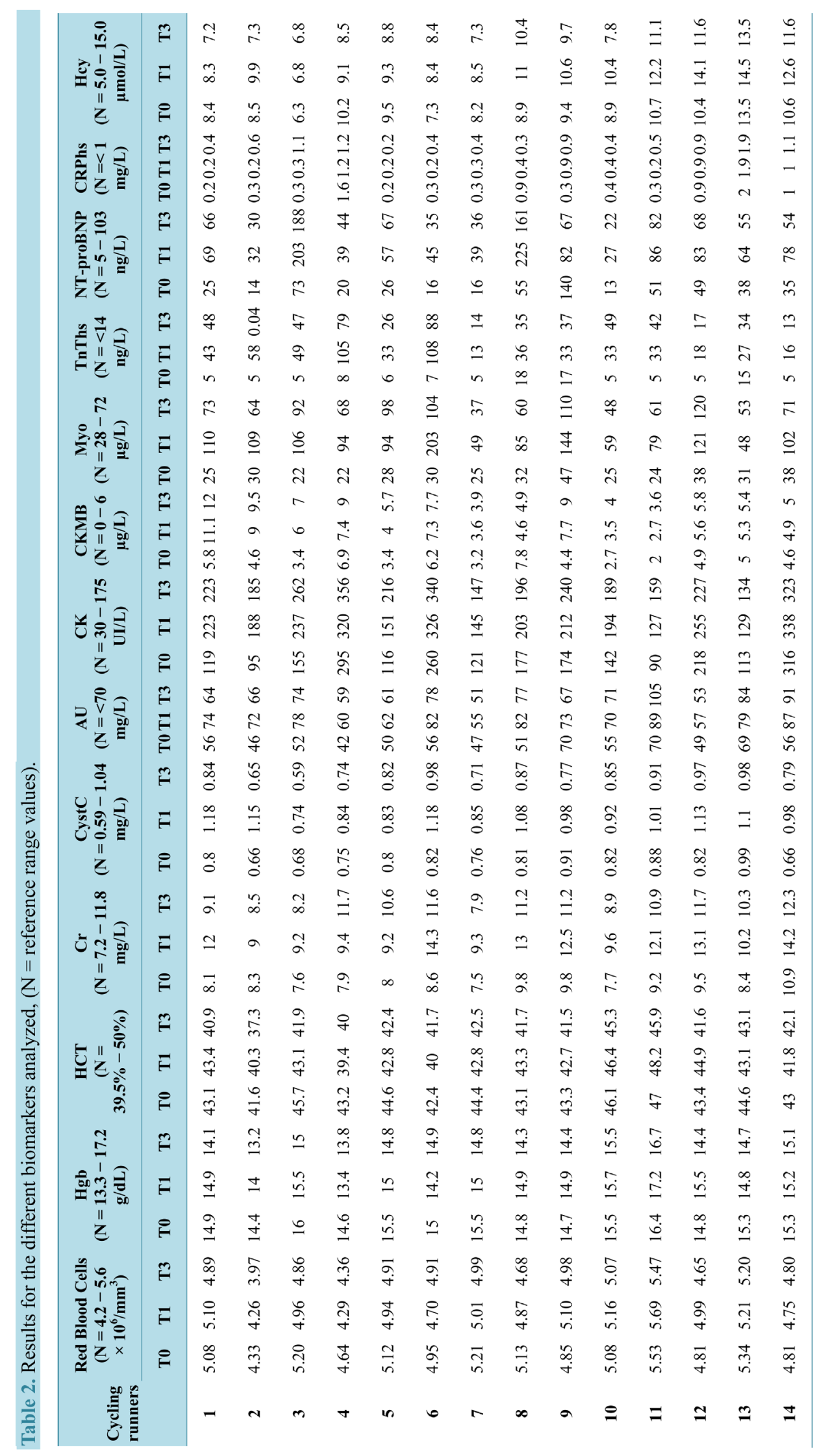




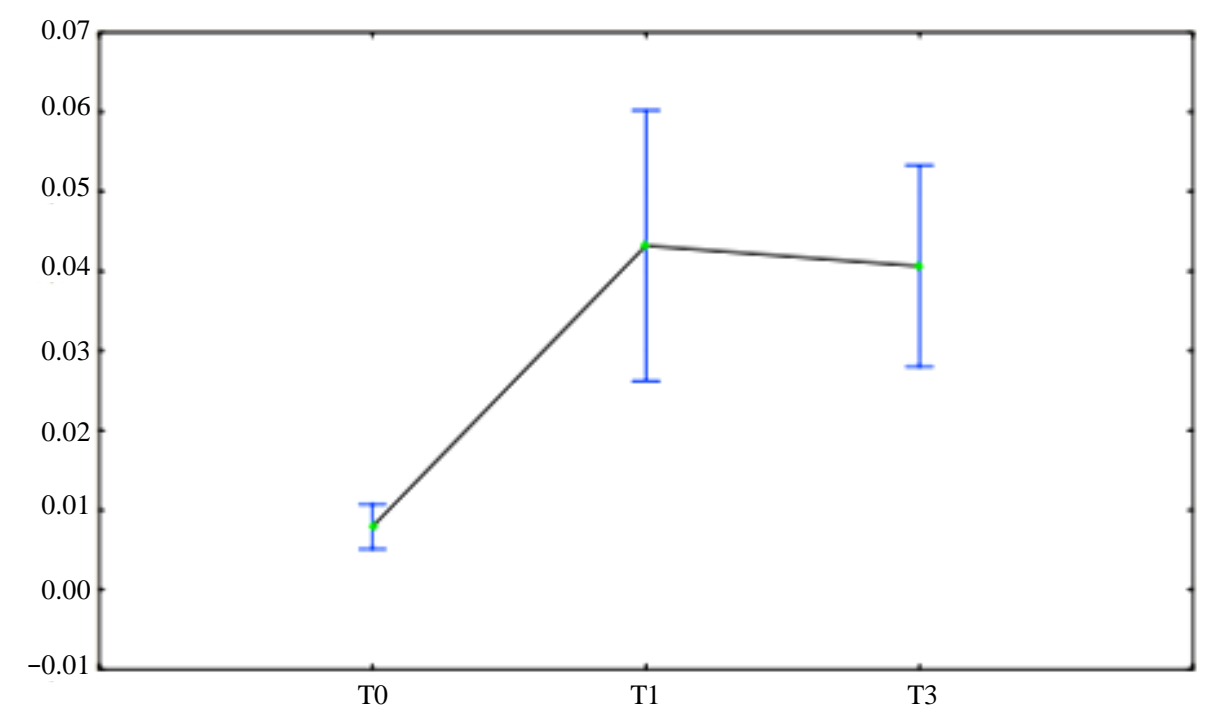

Figure 1. Evolution of hsTnT levels (ng/L) at the 3 times (T0, T1 and T3).

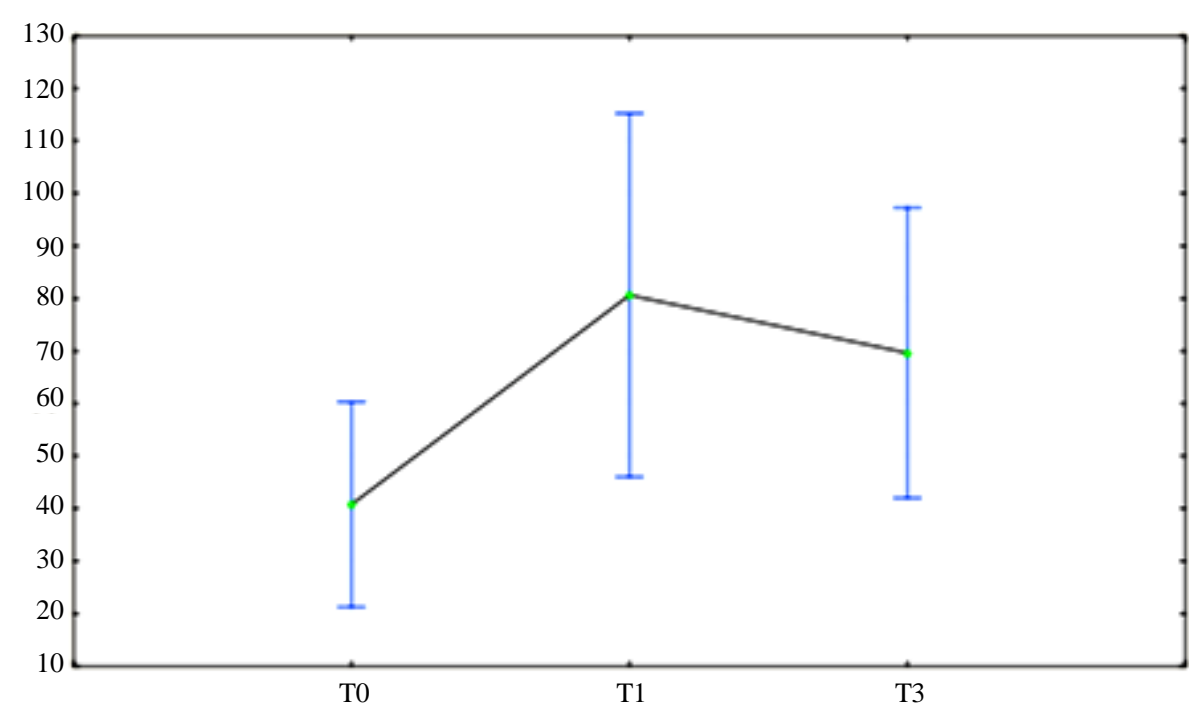

Figure 2. Evolution of NT-proBNP levels (ng/L) at the 3 times (T0, T1 and T3).

$\mathrm{T} 1(\mathrm{p}=0.0022)$ and a decrease between $\mathrm{T} 1$ and $\mathrm{T} 3(\mathrm{p}=0.0013)$. CK and CK-MB showed significant variation between T0 - T1 and T0 - T3 ( $<$ 0.0001), and between T0 - T1 ( $=0.0435)$ and between T0 - T3 ( $=0.0011)$ respectively.

\section{Discussion}

In cycling as in other types of strenuous exercise, there exists a risk of sudden death [21]-[23]. It is important both to understand its causes and to see if the behavior of certain biomarkers might highlight athletes at risk. Many reports describe changes in biomarkers after strenuous exercise [18] [24]-[32], but interpreting these changes, and notably distinguishing normal physiological responses from pathological changes, is not easy. Here we have focused on the kinetics of 14 different biomarkers (cytological, cardiospecific, muscle-related, or indicative of inflammation or renal function) in a group of young, trained cyclists participating in a $177 \mathrm{~km}$ cycling race. Our primary aim was to provide "typical" values of a broad panel of markers for this type of exercise and this category of subjects. We were also interested in any changes that might reflect exercise-related cardiac damage.

The cytological biomarkers hemoglobin and hematocrit were found, generally, to decrease both during and in 
the three hours following the race, probably because of substantial hydration and/or red cell destruction.

Between the start and the end of the race, most of the other biomarkers (CK, CK-MB, MYO, HsTnT, NT-proBNP, cystatin C) were found to increase [33]. A notable exception was the inflammation marker hsCRP, but in a study of 102 marathon runners, for example, high levels of this marker were not found until 24 hours after the end of the race [34]. Homocysteine levels showed no clear pattern of change in our study.

We were most interested in the cardiospecific biomarkers hsTnT, the marker of choice in the diagnosis of myocardial lesions [5] [8] [9], and NT-proBNP, used in the diagnosis and prognosis of cardiopulmonary disease [35].

At the start of the race, three of our cyclists showed levels of hsTnT below the reference level. At the end of the race, all of them showed a rise above the cut-off $14 \mathrm{ng} / \mathrm{L}$. It is worth noting that the cyclists with the highest pre-race levels showed only a moderate post-race increase. Other authors have reported elevated hsTnT levels after endurance exercise. Indeed, Middleton et al. [36] measured cTnT in a group of 9 males runners completing a laboratory based marathon. Therefore, the discrepancy in post-exercise cTnT release between previous study is likely due to the methodological differences and the timing of blood draws post-exercice. The hypothesis is that cTnT release is a normal physiologic response to exercise, and that without signs of cardiac pathology, it does not warrant worrying [37]. In their above-mentioned study of marathon runners, Scherr et al. [34] observed an interquartile range of 19.25 - $46.86 \mathrm{ng} / \mathrm{L}$ immediately after the race. This is in good agreement with our data, showing that at T1, three of the fourteen cyclists (21\%) had values below 19.25 and ten of them (71\%) had values below 46.86. According to these results we could think that we have too a notion of high and low responders as with the CK, well described in the work of Hody et al. [38]. It is noteworthy that 72 hours after finishing the marathon, all but four of the runners in Scherr's study [34] showed hsTnT levels that had returned to normal. Eight cyclists had a lower level at T3 than at T1, and six showed a higher level at T3 than at T1. In a laboratorybased marathon, Middleton et al. [36] observed measurable baseline levels of cTnT in 9 out of 9 healthy, well-trained male runners and a biphasic pattern of cTnT release in 8 of them. They concluded that the timing of blood draws can influence the results of cTnT measurements and may explain some discrepancies between studies. They also suggested that post-exercise cTnT release might reflect reversible cardiomyocyte membrane damage participating in a remodeling process.

Since cyclists 4 and 6 in Table 2 had levels above $100 \mathrm{ng} / \mathrm{L}$ at T1, a cut-off used in diagnosis of acute myocardial infarction, it is noteworthy that Scherr's team [34] sought and failed to detect any cardiac anomaly in the the five marathon runners having displayed the highest levels $(147-631 \mathrm{ng} / \mathrm{L})$ immediately after the race. Likewise, Shave et al. [37] propose that exercise-induced cardiac troponin release is not a marker of exercise-induced pathology, but likely a transitory physiological response to exercise, such as release from the cytosolic pool. In contrast, Nielan et al. observed a correlation between elevated cardiospecific biomarker levels and post-race diastolic dysfunction, increased pulmonary pressure, and right ventricular dysfunction. Discussing the significance and possible mechanisms of cTnT release in a 2010 review, Shave et al. [37] finally leave the question open, but conclude that the available data "support a mechanism of release that is unrelated to frank myocardial injury". In our study, all of the cyclists showed an increase in NT-proBNP at T1, but most of the levels remained within the reference range. This increase is probably due to increased parietal pressure, as an increase in NT-proBNP can be a physiological response to increased ventricular pressure at the end of the diastole [1]. BNP is indeed known to reduce tension in the myocardial wall by increasing natriuresis and causing vasodilation [13]. In the above-mentioned study by Scherr et al. [34], the interquartile range for the 102 marathon runners was 56.9 - 149.7, as compared to our 5 cyclists (31\%) below the lower limit of this range and 12 cyclists (87.5\%) below its upper limit. It would be interesting to see if these results for our limited population reflect a true difference between exercise types/age groups/training regimens. For two of our cyclists, the level attained was more than twice the upper limit of the reference range. Interestingly, these were not the same two subjects who showed the highest hsTnT levels. They had no particular physical complaints during or after the exercise, although according to Tschöpe et al. [39], this marker is useful for the detection of diastolic dysfunction in patients with exertional dyspnea. It seems that NT-proBNP is not a valid indicator of effort-induced myocardial ischemia [40]. Its elevation could then be considered a reaction to arterial hypertension induced by physical activity, since the myocardium is being put under important tensions during maximal efforts in aerobic exercises [41].

Creatine kinase is not a cardiospecific biomarker [38]. Our present results correspond very well with those of Brun et al. [42] [43], who observed an effort-intensity-related increase in CK. It should be mentioned, however, 
that the CK peak occurring after intense exercise typically occurs more than three hours after the end of the exercise [44]. In our cyclist study, it would have been interesting to measure biomarker levels after $24 \mathrm{~h}$ or $72 \mathrm{~h}$, but the three-hour wait after the race was already an obstacle to recruitment, explaining the small size of the studied group.

CK-MB is the CK isoenzyme most specific to cardiac muscle tissue, and it is important to pay attention to its variations [45], but it does not appear to be a good indicator of myocardial injury, especially in the context of strenuous exercise [4] [46].

Myoglobin has very low specificity as a cardiac biomarker [47], its one advantage in the context of acute myocardial infarction being its early rise (in contrast to cTnT). The changes in myoglobin and CK observed here probably reflect skeletal muscle damage rather than injury to cardiomyocytes. During the 1995 Boston Marathon, Siegel et al. [43] showed a post-effort increase of CK-MB and myoglobin, accompanied by an increase in hsTnI release, without demonstrating any presence of micro-infarction by myocardial scintigraphy.

What about the markers of renal function? Renal impairment is commonly observed after strenuous exercise. For example, in a study of 16 well-trained recreational cyclists participating in a $525 \mathrm{~km}$ extreme ultramarathon cycling (cumulative altitude: 12,600 m), Neumayr et al. [14] observed an average 20\% rise in serum creatinine (as compared to $29 \%$ in our study at $\mathrm{T} 1$ ) and $40 \%$ rise in uric acid (34\% in our study at $\mathrm{T} 1$ ). In a study of 70 marathon runners, Mingels et al. [48] observed a $41 \%$ increase in serum creatinine and a $21 \%$ increase in cystatin C (vs. 26\% for our cyclists). The latter investigators also described cystatin C as a more reliable marker of renal function [48]. In both of the studies just mentioned, the changes were attributed to reduced renal blood flow during exercise. In these studies and ours, the levels of renal-function biomarkers decreased in the hours following the race, probably because of hydration and the restoration of renal perfusion.

Our results are thus in line with the biomarker levels observed in various studies focusing on the effects of strenuous exercise [14]. Our multi-marker, the greatest originality of this study, approach allows us, however, to seek links between marker variations in individual athletes. Perhaps our most interesting results concern cyclist number 6 (Table 2): this cyclist showed the highest levels of hsTnT and myoglobin, high CK, and high levels of renal function markers. As myoglobinemia can be indicative of renal impairment [49] and as cTnT is degraded and then eliminated via the kidneys, this points to a particularly strong impact of exercise on renal function in this individual. The dehydration objectified by the hematocrit was probably the reflect of the renal impairment. Regarding hsTnT, however, it should be noted that the other cyclists showing an unusually high level of this biomarker had reasonable levels of renal markers.

Also interesting is the fact that both subjects showing the highest hsTnT levels at $\mathrm{T} 1$ had unexceptional NT-proBNP levels, and the two individuals having the highest NT-proBNP levels had unexceptional hsTnT values. These two markers would thus appear to give independent types of information on the effect of exercise on the heart. Due to the various mechanisms in cause, the impact on NT-pro-BNP and TnT is not the same. It should thus necessary to characterize the response of the left ventricle, the right ventricle and auricles to explain these different responses. To interpret these values, it is necessary to remember that the intra-individual biological variations can go up to $70 \%$ for NT-proBNP and 30\% for cTnT [50]. However, as variations of $100 \%$ for TnT and from 11\% to 200\% for NT-pro-BNP were observed, these observations could be really due to the effort and not due to intra-individual biological variations. Both of these markers are eliminated via the kidneys, but of course the serum level reflects a balance between release (to be explained) and degradation (to be measured). One of the high-NT-proBNP cyclists had fairly high levels of renal markers, but the other did not.

\section{Conclusion}

We provide simultaneous kinetics for 14 biomarkers (cytological, cardiospecific, and muscle-, inflammation-, and renal-function-related) in young, trained cyclists having completed a $177 \mathrm{~km}$ race (blood levels just before, just after, and 3 hours after the race). The results are in line with those of other studies on endurance athletes and are probably not indicative of any permanent damage to the heart. Concentrating on the most extreme observed rises in cardiospecific biomarkers, we note that the individuals showing the highest hsTNT levels are not the same as those showing the highest NT-proBNP levels. This suggests that independent mechanisms explain these unusually high levels. In one individual showing a high hsTNT level, renal impairment may be at least partially to blame. Thus in conclusion, we observed that physiological stress induced by a cycling race has transient consequences on cardiac muscle cells rather than an irreversible injury. Thus this study is reassuring for competitive 
cyclists but the accumulation of these transient damages could perhaps lead to a progressive cardiac fibrosis but thus is still to be demonstrated.

\section{References}

[1] World Health Organization (2007) Prevention of Cardiovascular Disease: Guidelines for Assessment and Management of Total Cardiovascular Risk. World Health Organization, Geneva.

[2] Flouris, A.D., Faught, B.E. and Klentrou, P. (2008) Cardiovascular Disease Risk in Adolescent Smokers: Evidence of a "Smoker Lifestyle". Journal of Child Health Care, 12, 221-231. http://dx.doi.org/10.1177/1367493508092509

[3] Biffl, W.L., Moore, F.A., Moore, E.E., Sauaia, A., Read, R.A. and Burch, J.M. (1994) Cardiac Enzymes Are Irrelevant in the Patient with Suspected Myocardial Contusion. The American Journal of Surgery, 168, 523-527. http://dx.doi.org/10.1016/S0002-9610(05)80115-1

[4] Hetland, O. and Dickstein, K. (1996) Cardiac Markers in the Early Hours of Acute Myocardial Infarction: Clinical Performance of Creatine Kinase, Creatine Kinase MB Isoenzyme (Activity and Mass Concentration), Creatine Kinase MM and MB Subform Ratios, Myoglobin and Cardiac Troponin T. Scandinavian Journal of Clinical and Laboratory Investigation, 56, 701-713. http://dx.doi.org/10.3109/00365519609088817

[5] Le Goff, C., Laurent, T., Kaux, J.F. and Chapelle, J.P. (2012) Intense Physical Exercise Related to the Emergent Generation of Cardiovascular Risk Markers: A Review. Biology of Sport, 29, 11-16. http://dx.doi.org/10.5604/20831862.979290

[6] Lefevre, G. (2002) Questions-réponses sur les dosages des troponines. Biotribune Magazine, 4, 36-37.

[7] Poortmans, J. (1995) La réponse rénale à l'exercice chez le sujet sain et pathologique. Néphrologie, 16, 317-324.

[8] Capolaghi, B., Charbonnier, B., Dumontet, M., Hennache, B., Henninot, J., Laperche, T., Lavoinne, A., Lefevre, G., Morin, C. and Pateron, D. (2005) Prescription, Assay and Interpretation of Cardiac Troponins Tests: Guidelines from SFBC-CNBC Troponin Working Group. Annales De Biologie Clinique (Paris), 63, 245-261.

[9] Giannitsis, E., Kurz, K., Hallermayer, K., Jarausch, J., Jaffe, A.S. and Katus, H.A. (2010) Analytical Validation of a High-Sensitivity Cardiac Troponin T Assay. Clinical Chemistry, 56, 254-261. http://dx.doi.org/10.1373/clinchem.2009.132654

[10] Agewall, S., Giannitsis, E., Jernberg, T. and Katus, H. (2011) Troponin Elevation in Coronary vs. Non-Coronary Disease. European Heart Journal, 32, 404-411. http://dx.doi.org/10.1093/eurheartj/ehq456

[11] Clerico, A. and Giannoni, A. (2010) Will High-Sensitive Troponin Immunoassays Lead to More Clarity or Confusion in Clinical Practice? Clinical Science (Lond), 119, 203-205. http://dx.doi.org/10.1042/CS20100234

[12] Kassab, A., Leban, N., Ferchichi, S., Feki, M., Ben Limem, H., Chaeib, L. and Miled, A. (2008) Oxidant Stress and Cardiovascular Absolute Risk in Tunisian Type 2 Diabetes. Annales De Biologie Clinique (Paris), 66, 151-156.

[13] Zeller, M., Cottin, Y., Laurent, Y., Danchin, N., L’Huillier, I., Collin, B., Desgres, J., Ravisy, J., Janin-Manificat, L., Makki, H., Jolak, M., Beer, J.C., Dentan, G., Gambert, P. and Wolf, J.E. (2004) N-Terminal Pro-Brain Natriuretic Peptide Levels in Patients with Non-ST-Elevation Myocardial Infarction. Cardiology, 102, 37-40. http://dx.doi.org/10.1159/000077002

[14] Neumayr, G., Pfister, R., Mitterbauer, G., Eibl, G. and Hoertnagl, H. (2005) Effect of Competitive Marathon Cycling on Plasma N-Terminal Pro-Brain Natriuretic Peptide and Cardiac Troponin T in Healthy Recreational Cyclists. The American Journal of Cardiology, 96, 732-735. http://dx.doi.org/10.1016/j.amjcard.2005.04.054

[15] de Lemos, J.A. and Morrow, D.A. (2003) Combining Natriuretic Peptides and Necrosis Markers in the Assessment of Acute Coronary Syndromes. Reviews in Cardiovascular Medicine, 4, S37-S46.

[16] Dixon, E.M., Kamath, M.V., McCartney, N. and Fallen, E.L. (1992) Neural Regulation of Heart Rate Variability in Endurance Athletes and Sedentary Controls. Cardiovascular Research, 26, 713-719. http://dx.doi.org/10.1093/cvr/26.7.713

[17] Neumayr, G., Gaenzer, H., Pfister, R., Sturm, W., Schwarzacher, S.P., Eibl, G., Mitterbauer, G. and Hoertnagl, H. (2001) Plasma Levels of Cardiac Troponin I after Prolonged Strenuous Endurance Exercise. The American Journal of Cardiology, 87, 369-371. http://dx.doi.org/10.1016/S0002-9149(00)01382-5

[18] Scharhag, J., Meyer, T., Auracher, M., Muller, M., Herrmann, M., Gabriel, H., Herrmann, W. and Kindermann, W. (2008) Exercise-Induced Increases in NT-proBNP Are Not Related to the Exercise-Induced Immune Response. British Journal of Sports Medicine, 42, 383-385. http://dx.doi.org/10.1136/bjsm.2007.039529

[19] Saravia, S.G., Knebel, F., Schroeckh, S., Ziebig, R., Lun, A., Weimann, A., Haberland, A., Borges, A.C. and Schimke, I. (2010) Cardiac Troponin T Release and Inflammation Demonstrated in Marathon Runners. Clinical Laboratory, 56, 51-58. 
[20] Laperche, T., Mestari, F. and Sabouret, P. (1995) Les marqueurs biochimiques de la nécrose myocardique. Sang Thrombose Vaisseaux, 7, 91-99.

[21] Lampman, R.M. and Schteingart, D.E. (1991) Effects of Exercise Training on Glucose Control, Lipid Metabolism, and Insulin Sensitivity in Hypertriglyceridemia and Non-Insulin Dependent Diabetes Mellitus. Medicine \& Science in Sports \& Exercise, 23, 703-712. http://dx.doi.org/10.1249/00005768-199106000-00009

[22] Jassal, D.S., Othman, R.A., Ahmadie, R., Fang, T., Zieroth, S., Fischer, G. and Moghadasian, M.H. (2009) The Role of Tissue Doppler Imaging in the Noninvasive Detection of Chronic Rejection after Heterotopic Cardiac Transplantation in Rats. Echocardiography, 26, 37-43. http://dx.doi.org/10.1111/j.1540-8175.2008.00751.x

[23] Frassl, W., Kowoll, R., Katz, N., Speth, M., Stangl, A., Brechtel, L., Joscht, B., Boldt, L.H., Meier-Buttermilch, R., Schlemmer, M., Roecker, L. and Gunga, H.C. (2008) Cardiac Markers (BNP, NT-pro-BNP, Troponin I, Troponin T) in Female Amateur Runners before and up until Three Days after a Marathon. Clinical Laboratory, 54, 81-87.

[24] Giannitsis, E., Roth, H.J., Leithauser, R.M., Scherhag, J., Beneke, R. and Katus, H.A. (2009) New Highly Sensitivity Assay Used to Measure Cardiac Troponin T Concentration Changes during a Continuous 216-km Marathon. Clinical Chemistry, 55, 590-592. http://dx.doi.org/10.1373/clinchem.2008.116566

[25] Hubble, K.M., Fatovich, D.M., Grasko, J.M. and Vasikaran, S.D. (2009) Cardiac Troponin Increases among Marathon Runners in the Perth Marathon: The Troponin in Marathons (TRIM) Study. The Medical Journal of Australia, 190, 9193.

[26] Koller, A. and Schobersberger, W. (2009) Cytosolic Release of Cardiac Troponin after Marathon Running. The American Journal of Cardiology, 104, 742-743. http://dx.doi.org/10.1016/j.amjcard.2009.06.001

[27] Kratz, A., Lewandrowski, K.B., Siegel, A.J., Chun, K.Y., Flood, J.G., Van Cott, E.M. and Lee-Lewandrowski, E. (2002) Effect of Marathon Running on Hematologic and Biochemical Laboratory Parameters, Including Cardiac Markers. American Journal of Clinical Pathology, 118, 856-863. http://dx.doi.org/10.1309/14TY-2TDJ-1X0Y-1V6V

[28] Nie, J., George, K.P., Tong, T.K., Gaze, D., Tian, Y., Lin, H. and Shi, Q. (2011) The Influence of a Half-Marathon Race upon Cardiac Troponin T Release in Adolescent Runners. Current Medicinal Chemistry, 18, 3452-3456. http://dx.doi.org/10.2174/092986711796642625

[29] Olivier, N., Legrand, R., Rogez, J., Berthoin, S. and Weissland, T. (2008) Arrêt de l'entrainement et déconditionnement à l'effort aérobie. Science \& Sports, 23, 136-144. http://dx.doi.org/10.1016/j.scispo.2008.02.006

[30] Schneider, C.M., Dennehy, C.A., Rodearmel, S.J. and Hayward, J.R. (1995) Effects of Physical Activity on Creatine Phosphokinase and the Isoenzyme Creatine Kinase-MB. Annals of Emergency Medicine, 25, 520-524. http://dx.doi.org/10.1016/S0196-0644(95)70270-9

[31] Totsuka, M., Nakaji, S., Suzuki, K., Sugawara, K. and Sato, K. (2002) Break Point of Serum Creatine Kinase Release after Endurance Exercise. Journal of Applied Physiology, 93, 1280-1286. http://dx.doi.org/10.1152/japplphysiol.01270.2001

[32] Tolkin, L., Goldstein, B. and Rott, D. (2009) Elevation of Cardiac Troponin T after Running Is Not Limited to Marathon Runners. Cardiology, 112, 188-190. http://dx.doi.org/10.1159/000149153

[33] Le Goff, C., Kaux, J.F., Goffaux, S. and Cavalier, E. (2015) Cardiac Biomarkers and Cycling Race. Journal of Sports Science and Medicine, 14, 475-476.

[34] Scherr, J., Braun, S., Schuster, T., Hartmann, C., Moehlenkamp, S., Wolfarth, B., Pressler, A. and Halle, M. (2011) 72-h Kinetics of High-Sensitive Troponin T and Inflammatory Markers after Marathon. Medicine \& Science in Sports \& Exercise, 43, 1819-1827. http://dx.doi.org/10.1249/MSS.0b013e31821b12eb

[35] Hunt, P.J., Richards, A.M., Nicholls, M.G., Yandle, T.G., Doughty, R.N., Espiner, E.A. (1997) Immunoreactive Amino-Terminal Pro-Brain Natriuretic Peptide (NT-PROBNP): A New Marker of Cardiac Impairment. Clinical Endocrinology (Oxford), 47, 287-296. http://dx.doi.org/10.1046/j.1365-2265.1997.2361058.x

[36] Middleton, N., George, K., Whyte, G., Gaze, D., Collinson, P. and Shave, R. (2008) Cardiac Troponin T Release Is Stimulated by Endurance Exercise in Healthy Humans. Journal of the American College of Cardiology, 52, 1813-1814. http://dx.doi.org/10.1016/j.jacc.2008.03.069

[37] Shave, R. and Oxborough, D. (2012) Exercise-Induced Cardiac Injury: Evidence from Novel Imaging Techniques and Highly Sensitive Cardiac Troponin Assays. Progress in Cardiovascular Diseases, 54, 407-415. http://dx.doi.org/10.1016/j.pcad.2012.01.007

[38] Hody, S., Rogister, B., Leprince, P., Laglaine, T. and Croisier, J.L. (2013) The Susceptibility of the Knee Extensors to Eccentric Exercise-Induced Muscle Damage Is Not Affected by Leg Dominance but by Exercise Order. Clinical Physiology and Functional Imaging, 33, 373-380. http://dx.doi.org/10.1111/cpf.12040

[39] Tschope, C., Kasner, M., Westermann, D., Walther, T., Gaub, R., Poller, W.C. and Schultheiss, H.P. (2005) Elevated NT-ProBNP Levels in Patients with Increased Left Ventricular Filling Pressure during Exercise Despite Preserved Systolic Function. Journal of Cardiac Failure, 11, S28-S33. http://dx.doi.org/10.1016/j.cardfail.2005.04.013 
[40] De Greef, J., Funk, M., Vermaak, W.J., Perumal, N.S., Libhaber, C.D. and Vangu, M.D. (2008) NT-proBNP and the Diagnosis of Exercise-Induced Myocardial Ischaemia. Cardiovascular Journal of Africa, 19, 264-267.

[41] Neumayr, G., Pfister, R., Hoertnagl, H., Mitterbauer, G., Prokop, W. and Joannidis, M. (2005) Renal Function and Plasma Volume Following Ultramarathon Cycling. International Journal of Sports Medicine, 26, 2-8. http://dx.doi.org/10.1055/s-2004-815717

[42] Brun, J.F., Rama, D., Bouix, O., Supparo, I., Larue, C., Calzolari, C., Lagrange, M.C., Heinen, C., Micallef, J.P. and Orsetti, A. (1993) Variations physiologiques de la myosinémie en relation avec l'activité musculaire. Science \& Sports, 8, 261-268. http://dx.doi.org/10.1016/S0765-1597(05)80107-8

[43] Brun, J.F., Fédou, C., Varlet-Marie, E., Aloulou, I. and Mercier, J. (2004) Sémiologie du surentrainement. Sport \& Santé, 18-28.

[44] Siegel, A.J., Sholar, M., Yang, J., Dhanak, E. and Lewandrowski, K.B. (1997) Elevated Serum Cardiac Markers in Asymptomatic Marathon Runners after Competition: Is the Myocardium Stunned? Cardiology, 88, 487-491. http://dx.doi.org/10.1159/000177396

[45] Apple, F.S., Christenson, R.H., Valdes Jr., R., Andriak, A.J., Berg, A., Duh, S.H., Feng, Y.J., Jortani, S.A., Johnson, N.A., Koplen, B., Mascotti, K. and Wu, A.H. (1999) Simultaneous Rapid Measurement of Whole Blood Myoglobin, Creatine Kinase MB, and Cardiac Troponin I by the Triage Cardiac Panel for Detection of Myocardial Infarction. Clinical Chemistry, 45, 199-205.

[46] Siegel, A.J., Lewandrowski, E.L., Chun, K.Y., Sholar, M.B., Fischman, A.J. and Lewandrowski, K.B. (2001) Changes in Cardiac Markers Including B-Natriuretic Peptide in Runners after the Boston Marathon. The American Journal of Cardiology, 88, 920-923. http://dx.doi.org/10.1016/S0002-9149(01)01910-5

[47] Lewandrowski, K., Chen, A. and Januzzi, J. (2002) Cardiac Markers for Myocardial Infarction. A Brief Review. American Journal of Clinical Pathology, 118, S93-S99.

[48] Mingels, A., Jacobs, L., Kleijnen, V., Wodzig, W. and Dieijen-Visser, M. (2009) Cystatin C a Marker for Renal Function after Exercise. International Journal of Sports Medicine, 30, 668-671. http://dx.doi.org/10.1055/s-0029-1220733

[49] Melamed, I., Romem, Y., Keren, G., Epstein, Y. and Dolev, E. (1982) March Myoglobinemia: A Hazard to Renal Function. Archives of Internal Medicine, 142, 1277-1279. http://dx.doi.org/10.1001/archinte.1982.00340200035009

[50] Ricos, C., Alvarez, V., Cava, F., Garcia-Lario, J.V., Hernandez, A., Jimenez, C.V., Minchinela, J., Perich, C. and Simon, M. (1999) Current Databases on Biologic Variation: Pros, Cons and Progress. Scandinavian Journal of Clinical and Laboratory Investigation, 59, 491-500. http://dx.doi.org/10.1080/00365519950185229

\section{Submit or recommend next manuscript to SCIRP and we will provide best service for you:}

Accepting pre-submission inquiries through Email, Facebook, LinkedIn, Twitter, etc. A wide selection of journals (inclusive of 9 subjects, more than 200 journals)

Providing 24-hour high-quality service

User-friendly online submission system

Fair and swift peer-review system

Efficient typesetting and proofreading procedure

Display of the result of downloads and visits, as well as the number of cited articles

Maximum dissemination of your research work

Submit your manuscript at: http://papersubmission.scirp.org/ 